\title{
Estudo da variação granulométrica de agregado sintético para Fabricação de placas pré-moldadas de concreto não estrutural
}

\section{Study of the granulometric variation of synthetic aggregate for the manufacture of pre-cast non structural concrete slabs}

\author{
Fagner Fonseca Santos ${ }^{1}$, Fernando Luiz de Andrade Santos ${ }^{1}$, \\ José Nilton Soares Santos ${ }^{1}$, Mandarlan Hallei Nascimento Pereira ${ }^{1}$, \\ Vanessa Gentil Almeida ${ }^{2}$, Fernanda Martins Cavalvante de Melo ${ }^{2}$ \\ Herbet Alves de Oliveira $^{2}$, Shevine Silva Oliveira Risso ${ }^{3}$
}

\footnotetext{
${ }^{1}$ Grupo de Pesquisa do Curso de Engenharia Civil - Instituto Federal de Sergipe, campus Estância, Sergipe, SE e-mail: faagnerfonseca@gmail.com, andradefernando08@gmail.com, niltonsoares8@gmail.com, mandarlanhallei@yahoo.com.br

${ }^{2}$ Professor, Instituto Federal de Sergipe, campus Estância, Sergipe, SE.

e-mail: vanessa.gentil@hotmail.com,Fernanda.melo.ifs@gmail.com, herbetalves148@gmail.com

${ }^{3}$ Mestre em Energia, UFABC, Santo André, SP

e-mail: shevine.oliveira@gmail.com
}

\section{RESUMO}

Os concretos leves podem ser utilizados na construção civil como isolamento térmico e acústico, cobrimento de lajes, produção de placas, entre outros. Produzidos a partir de argila expandida, que apresentam massa unitária entre 300 e $2000 \mathrm{~kg} / \mathrm{m}^{3}$, os materiais garantem redução do peso de estruturas favorecendo a diminuição dos custos com as fundações. Neste trabalho, foi estudado o melhor arranjo granulométrico de argilas expandidas de granulometrias de diâmetro 22,15 e $5 \mathrm{~mm}$, com o fim de produzir placas de concreto com baixo peso específico e sem alteração da resistência mecânica à flexão em três pontos, em comparação as que são confeccionadas a partir de britas convencionais. As matérias-primas foram caracterizadas por meio da massa unitária, massa específica, absorção de água, análise granulométrica, análise química por fluorescência de raios X (FRX) e foram determinadas as fases presentes por difratometria de raios X-DRX. Em seguida, foi utilizado o diagrama triangular de Winkler com o intuito de obter as massas unitárias e os respectivos empacotamentos. Este diagrama é pouco difundido no segmento de construção civil e pode ser muito útil para realizar misturas de até três componentes e avaliar qualquer propriedade, definindo uma região ótima de trabalho. Foram escolhidos pontos do diagrama com diferentes massas unitárias, para produção de corpos de prova de concreto com argila expandida e com o agregado convencional. Os corpos de prova foram submetidos ao ensaio de resistência mecânica à flexão em três pontos e densidade aparente. Os resultados mostraram que houve redução de $30 \%$ a $50 \%$ no peso das peças, sem alteração da resistência mecânica nas formulações A e D. Vale ressaltar que a densidade e resistência mecânica das formulações A e D foram as maiores em relação às argilas expandidas, provavelmente devido ao menor abatimento apresentado além da elevada massa unitária mostrada no diagrama ternário.

Palavras-chave: Argila expandida, concreto, placas.

\section{ABSTRACT}

Lightweight concretes can be used in civil construction, such as thermal and acoustic insulation, slab cover, plate production and others. Produced from expanded clay, which have a unit mass between 300 and $2000 \mathrm{~kg}$ $/ \mathrm{m}^{3}$, the materials guarantee a reduction of the weight of structures favoring the reduction of the costs with the foundations. In this work, the best granulometric arrangement of expanded clays of 22,15 and $5 \mathrm{~mm}$ diameter granulometry was studied in order to produce concrete slabs with low specific gravity and with no 
change in mechanical resistance to flexural strength, compared to those made with from conventional crushers. The raw materials were characterized by means of unit mass, specific mass, water absorption, particle size analysis, chemical analysis and X-ray diffraction. Next, Winkler's triangular diagram was used in order to obtain the unit masses and The respective packaging. This diagram is not very widespread in the construction segment and can be very useful for mixing up to three components and evaluating any property, defining an optimum working region. The points of the diagram were chosen with different unit masses for the production of test specimens with expanded clay and with the conventional aggregate. The specimens were submitted to three - point flexural strength and apparent density test. The results showed that there was a reduction of 30\% to $50 \%$ in the weight of the pieces, without altering the mechanical resistance in formulations A and D. It is worth mentioning that the density and mechanical strength of the formulations A and D were the largest in relation to the lightweigth, probably due to the smaller slump presented, besides the high unit mass presented in the ternary diagram.

Keywords: Lightweight, concrete, plates.

\section{INTRODUÇÃO}

Placas de concreto são utilizadas amplamente em todo o mundo para aplicações diversas tanto no revestimento de paredes internas como externas. Além disso, são utilizadas para satisfazer às demandas da construção civil na produção de caixas de ar-condicionado, tampas de bueiros de esgoto e de água e em de peças para decoração (como armários e guarda-roupas, por exemplo) [1]. Essas placas são produzidas por meio de uma mistura de cimento, areia, brita e água. No entanto, o manuseio, transporte e assentamento das placas tornamse dificultosos devido ao seu elevado peso. Uma alternativa para solucionar o problema é utilizar argila expandida na sua formulação que apresenta baixo peso específico, desde que não altere as propriedades como resistência mecânica e durabilidade dessas peças [2]. Agregado leve sintético é definido como um conjunto de grãos naturais processados ou manufaturados, que apresentam diferentes tamanhos e que são interligados por material aglomerante. Os agregados sintéticos são produzidos através de argilas ou subproduto de resíduos, que normalmente geram um produto com peso específico inferior ao da pedra britada e com elevada absorção de água. Os agregados leves podem ser obtidos pelo processo de queima em forno rotativo e apresentam granulometria variada, formato arredondado regular e estrutura interna formada por uma massa esponjosa, envolto por uma camada com baixa permeabilidade, que diminui significativamente a absorção de água. Sua sinterização é feita entre 1100 e $1350^{\circ} \mathrm{C}$, e sua matéria-prima podem ser divididas em três grupos: matéria-prima natural, como vermiculita, argila, ardósia, folhelhos, os resíduos diversos ou mistura de resíduos e matérias primas naturais com a incorporação de aditivos. Essas matérias primas em geral contêm de 7 a $8 \%$ de $\mathrm{Fe} 2 \mathrm{O} 3$, no máximo $25 \%$ Al2O3 e cerca de $1 \%$ de carbonatos, além de apresentar sulfatos e matéria orgânica, e um pH superior a 5 [3].

Segundo Chandra (2002) [4], a resistência mecânica depende das características das matérias-primas, bem como do processo de produção utilizado. Agregados produzidos com uma distribuição uniforme de pequenos poros apresentam maiores resistências que agregados com poucos poros de grandes diâmetros. Os agregados sintéticos leves possuem elevada absorção de água e baixa densidade aparente, comparados com a pedra britada, o que facilita a aderência à pasta cimentícia e ao processo de cura interna quando se produz concreto [5-7]. Segundo Bogas (2013) [8], a argila expandida pode reduzir em 30 a 50\% o peso de uma estrutura, e a resistência mecânica a compressão pode ainda alcançar até $45 \mathrm{MPa}$, obtendo peso específico de 1700 $\mathrm{kg} / \mathrm{m} 3$, comparados com a brita que oscila de 2600 a $2700 \mathrm{~kg} / \mathrm{m}^{3}$.

A utilização de agregados sintéticos em construção é remota, e estudos já foram realizados abordando a contribuição do formato da partícula bem como a densidade das misturas nas propriedades finais do concreto. No entanto, existem poucos trabalhos que abordam o diagrama ternário de Winkler como metodologia de escolha prévia de misturas antes de se produzir o concreto.

Neste trabalho, uma empresa produtora de peças pré-fabricadas de concreto desejava reduzir o peso das suas placas produzidas com cimento, brita e areia, devido a dificuldades que clientes têm manifestado no transporte e, sobretudo, no manuseio das placas durante o assentamento. Proporcionalmente, a resistência mecânica à flexão em três pontos deve ser mantida para não comprometer a durabilidade e manuseio delas. Para isso, foram produzidas placas com cimento, areia e três tipos de argila expandida com diâmetros de 22, 15 e $5 \mathrm{~mm}$, mantendo-se constante o fator água/cimento.

As matérias-primas foram caracterizadas por meio da massa unitária, massa específica, absorção de água, análise granulométrica, análise química por fluorescência de raios $\mathrm{X}$ e difratometria de raios $\mathrm{X}$. Foram produzidos corpos de prova de concreto, os quais foram submetidos ao ensaio de resistência mecânica à flexão em três pontos e densidade aparente, após cura aos 28 dias. 


\section{MATERIAIS E MÉTODOS}

\subsection{Caracterização das matérias-primas}

As matérias-primas foram caracterizadas pelos seguintes ensaios tecnológicos: massa unitária (areia, cimento e argila expandida) analisada de acordo com NBR NM 45/2006 [9]. Este ensaio consiste em verter para uma caixa de volume conhecido as amostras. Em seguida, nivela-se com auxílio de uma régua e pesa-se. A razão entre o peso das amostras e o volume ocupado nos fornece a massa unitária. A distribuição granulométrica (areia, brita e argila expandida) foi realizada pelo método do peneiramento conforme NBR NM 248/2003 [10]. A massa específica (areia) foi executada pelo método do picnômetro segundo a NBR 8916/2015 [11], enquanto a argila expandida foi previamente triturada e passada na peneira ABNT \# 200 meshes e submetida ao ensaio de densidade pelo picnômetro de hélio, cuja técnica permite obter o volume de um sólido pela redução do fluxo de gás, em uma câmara de medida, causada pela presença de um sólido, quando o gás hélio penetra nos poros e nas superfícies irregulares. Assim, o volume obtido permite determinar a densidade aparente de um sólido [12]. O ensaio de absorção de água (brita e argila expandida) pela norma NBR NM $53 / 2009[13]$.

Os percentuais dos óxidos constituintes das amostras foram determinados através de medidas pela técnica de fluorescência de raios X (FRX). As medidas foram realizadas em vácuo, em um equipamento da marca Bruker, modelo S4 Pioneer, utilizando amostras com massa em torno de $10 \mathrm{~g}$ que foram prensadas no formato de corpos cilíndricos com diâmetro $20 \mathrm{~mm}$ e espessura de $3 \mathrm{~mm}$, aproximadamente. Com o objetivo de caracterizar a argila expandida utilizada identificando os minerais constituintes para futuras pesquisas, foi realizada análise microestrutural por difratometria de raios X para identificação das fases cristalinas, de acordo com os padrões obtidos no banco de dados do ICSD (Inorganic Crystal Structure Database). Os padrões de difração foram obtidos com um equipamento Rigaku D-MAX 100, usando radiação $\mathrm{Cu} \operatorname{Ka}(\lambda=1,5418 \AA)$ em modo de varredura contínua, em intervalo angular de 3 a $80^{\circ} \mathrm{com}$ velocidade de varredura de $1^{\circ} / \mathrm{min}$ [14].

\subsection{Formulações e ensaios tecnológicos}

Foi utilizada nesta pesquisa a argila expandida fornecida pela CINEXPAN [15] de diâmetros de 22, 15 e 5 $\mathrm{mm}$, areia lavada da região e cimento Portland CP IV. Após a realização dos ensaios de caracterização dos agregados, iniciou-se a produção dos concretos definidos na Tabela 1. Como primeiro passo desta etapa, fezse a produção do concreto padrão a partir dos agregados naturais, fixando-se o abatimento medido pelo método do tronco de cone como meta em $12 \pm 3 \mathrm{~cm}[16]$.

Para a produção dos traços de concreto, alguns ajustes foram necessários. Primeiramente, foi realizada uma compensação do volume dos agregados de argila expandida, a serem utilizados nos traços prédeterminados, pois a simples substituição da massa do agregado natural pela massa do agregado de argila expandida iria resultar em traços com volumes maiores de agregados de argila expandida, uma vez que a massa específica dos agregados de argila expandida é menor que a massa específica dos agregados naturais [17].

Conforme apresentado na Tabela 1, foi utilizada uma formulação padrão de produção de placas produzidas com brita convencional e quatro formulações utilizando argila expandida, cujo objetivo era substituir a brita convencional e obter resistência mecânica à flexão de pelo menos 3,5 $\mathrm{MPa}$, com a menor densidade possível, para redução do peso da estrutura.

Inicialmente, foi realizada a medida da densidade aparente no estado solto, utilizando as três argilas e foram escolhidos alguns pontos do diagrama ternário das massas unitárias que estão plotadas no diagrama ternário de Winkler, conforme apresentado na Figura 1. Nesse diagrama, é possível realizar misturas com três componentes totalizando $100 \%$ do volume de agregados de uma dada formulação. Como exemplo: a mistura B possui argilas de $\varnothing 22(50 \%), \emptyset 15,(25 \%)$ e $\varnothing 5,(25 \%)$. A partir do diagrama, podem-se definir pontos de mistura, com diferentes massas unitárias e os respectivos empacotamentos dos agregados, para posterior produção dos corpos de prova de concreto. O diagrama pode ser útil também para avaliar variações de composição química, ou qualquer outra propriedade desde que seja até três componentes. 
Tabela 1: Formulações utilizadas em traço $\mathrm{kg} / \mathrm{m}^{3}$.

\begin{tabular}{l|c|c|c|c|c}
\hline CONSTITUINTES & PADRÃO & A & B & C & D \\
\hline Cimento CP IV & 389,7 & 362,8 & 349,7 & 330,1 & 364,9 \\
\hline Areia lavada & 1169,1 & 1088,5 & 1047,0 & 990,0 & 1094,9 \\
\hline Brita zero & 779,4 & - & - & - & - \\
\hline Argila Expandida Ø 22 mm & - & 235,8 & 174,9 & 99,0 & 474,3 \\
\hline Argila Expandida Ø 15 mm & - & 235,8 & 349,7 & 99,0 & 109,5 \\
\hline Argila Expandida Ø 5 mm & - & 235,8 & 174,9 & 495,0 & 109,5 \\
\hline Água & 233,2 & 217,8 & 209,8 & 198,0 & 218,9 \\
\hline a/c & 0,60 & 0,60 & 0,60 & 0,60 & 0,60 \\
\hline
\end{tabular}

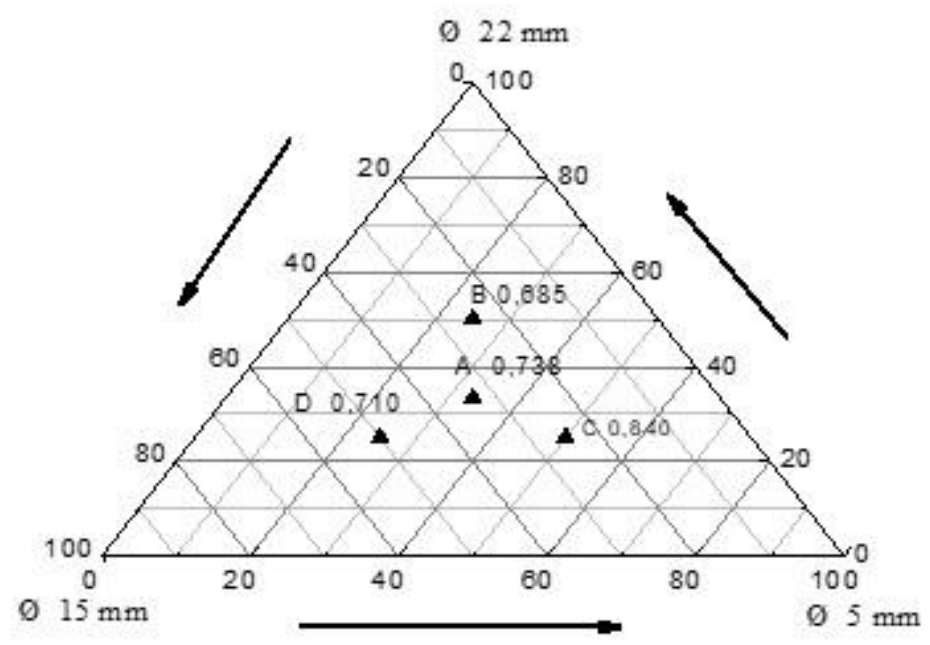

Figura 1: Diagrama de Winkler da densidade aparente dos agregados.

\subsection{Preparação dos corpos de prova}

As misturas foram produzidas em betoneira de capacidade de $200 \mathrm{~L}$, obedecendo a uma relação de a/c de 0,60. As argilas expandidas utilizadas nas formulações foram previamente imersas em água, pelo tempo de duas horas para evitar que absorvessem a água de amassamento e, assim se alterasse a consistência da mistura [1820]. Assim, ao adicionar água ao concreto, foi levada em conta a água absorvida pelo agregado e descontada do cálculo do traço. Já a brita apresenta baixa absorção de água não sendo necessário realizar préumidificação.

Foram moldados cinco corpos de prova prismáticos de cada formulação de dimensões $20 \times 5 \times 5 \mathrm{~cm}$, e desmoldados após $24 \mathrm{~h}$. Em seguida, os corpos de prova foram submetidos à cura por imersão em água por 28 dias para, posteriormente realizar o ensaio de resistência mecânica à flexão em três pontos e densidade aparente. Foram também produzidas placas de concreto de dimensões 50x50x5 cm para avaliação da densidade conforme apresentado na Figura 2. 


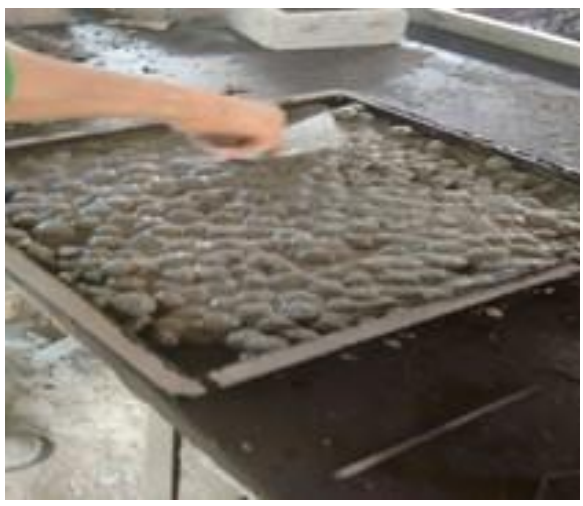

Figura 2: Placas de concreto produzidas com argila expandida.

\subsection{Ensaios tecnológicos}

Ensaios de Resistência mecânica à flexão em três pontos (TRF): para este ensaio foram utilizadas amostras prismáticas de dimensões $(20$ x 5 x 5) cm. Foi utilizado um tensiômetro da marca Shimadzu, modelo EM KN 30 com velocidade de aplicação de carga de $1 \mathrm{~mm} / \mathrm{min}$, seguindo a norma NBR 12142/2010 [21], cujos resultados podem ser expressos pela média de acordo com a equação Eq. (1), em que $P$ é a carga aplicada em $(\mathrm{N}), L$ é a distância entre apoios, igual a $120 \mathrm{~mm}$ (a) espessura e (b) a largura em $\mathrm{mm}$ do corpo de prova. $\mathrm{Na}$ Figura 3, é possível observar foto do ensaio.

$$
R F=3 P L / 2 a^{2} b
$$

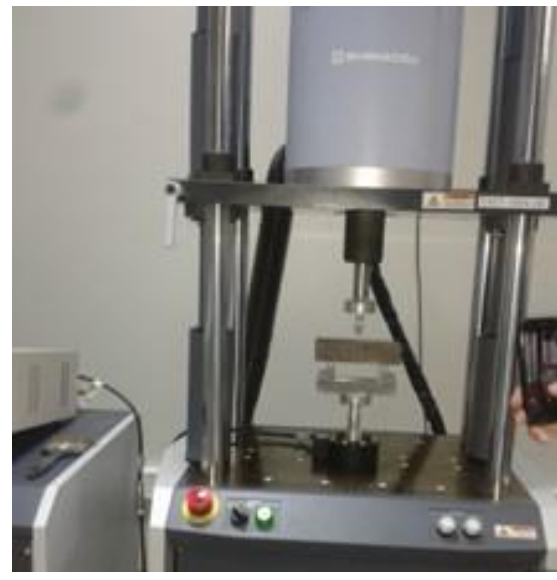

Figura 3: Ensaio realizado de resistência mecânica à flexão em três pontos (RMF).

Ensaio de densidade aparente $(D)$ : Os corpos de prova após a cura aos 28 dias foram secos em estufa à temperatura de $50 \pm 10^{\circ} \mathrm{C}$ até peso constante, e em seguida foram tomadas as medidas em $(\mathrm{mm})$ por meio de um paquímetro digital de resolução $0,01 \mathrm{~mm}$ e pesados em balança digital da marca marte de resolução $0,01 \mathrm{~g}$. A densidade pode ser expressa pela Eq. (2) em que $m$ corresponde a massa em $(\mathrm{g})$ e $v$ o volume em $\left(\mathrm{cm}^{3}\right)$.

$$
D=m / v
$$

\section{RESULTADOS E DISCUSSÃO}

\subsection{Massa unitária / Massa específica / Absorção de água}

De acordo com a Tabela 2, a massa unitária bem como a massa específica está de acordo com as especificações de Isaia (2005) [22]. A massa unitária e massa específica das argilas expandidas são baixas e proporcionalmente apresentam elevado teor de absorção de água em relação à brita, devido a elementos expansivos 
utilizados no processo produtivo do agregado. Elementos tais como óleo, serragem, matéria orgânica presente nas argilas, as quais se dissociam após queima, deixando poros, além das condições de queima como ciclo e temperatura [23-24]. A absorção de água dos agregados e sua porosidade aparente interferem significantemente nas propriedades dos concretos no estado fresco e no processo de hidratação do cimento. Em alguns casos, quando o agregado apresenta valores muito elevados de absorção de água, faz-se necessária uma présaturação do agregado antes da sua utilização [25-26]. A alta absorção de água das argilas expandidas pode alterar desfavoravelmente as propriedades do concreto no estado endurecido, causando aumento da retração por secagem [26-27], e redução da massa específica. Por outro lado, a elevada absorção melhora a aderência na zona de transição entre o concreto e o agregado [28].

Adicionalmente, uma dificuldade encontrada é que ao se adicionar água ao concreto, parte dela entra nos poros dos agregados e acaba dificultando o desenvolvimento da resistência [28-29]. Neste trabalho, foi avaliada preliminarmente a relação entre as misturas e o empacotamento, que, de forma indireta, foi observado pela massa unitária. Nota-se na Tabela 2 que a massa unitária entre os tipos de argila expandida são diferentes, sobretudo devido às condições de produção. Os agregados de diâmetro maiores apresentam, por sua vez, massa unitária mais baixa $\emptyset 22\left(0,524 \mathrm{~g} / \mathrm{cm}^{3}\right)$.

Tabela 2: Ensaio de caracterização das matérias-primas.

\begin{tabular}{|c|c|c|c|}
\hline MATÉRIA - PRIMA & $\begin{array}{c}\text { MASSA UNITÁ- } \\
\text { RIA } \\
\left(\mathbf{g} / \mathrm{cm}^{3}\right)\end{array}$ & $\begin{array}{c}\text { MASSA ESPE- } \\
\text { CÍFICA } \\
\left(\mathbf{g} / \mathrm{cm}^{3}\right)\end{array}$ & $\begin{array}{c}\text { ABSORÇÃO DE } \\
\text { ÁGUA } \\
(\%)\end{array}$ \\
\hline Areia & $1,63 \pm 0,15$ & $2,65 \pm 0,01$ & - \\
\hline Brita & $1,51 \pm 0,05$ & $2,64 \pm 0,01$ & $0,4 \pm 0,2$ \\
\hline Cimento & $1,18 \pm 0,05$ & $3,15 \pm 0,01$ & - \\
\hline Argila Expandida $\emptyset 22 \mathrm{~mm}$ & $0,524 \pm 0,05$ & $2,58 \pm 0,01$ & $9,6 \pm 0,1$ \\
\hline Argila Expandida $\emptyset 15 \mathrm{~mm}$ & $0,660 \pm 0,03$ & $2,59 \pm 0,01$ & $11,3 \pm 0,2$ \\
\hline Argila Expandida $\varnothing 5 \mathrm{~mm}$ & $0,845 \pm 0,03$ & $2,60 \pm 0,01$ & $6,5 \pm 0,1$ \\
\hline
\end{tabular}

\subsection{Análise química}

Os resultados de análise química apresentados na Tabela 3 mostram que a brita é rica em sílica e álcalis, o que caracteriza um material constituído basicamente por quartzo e feldspato [23]. A argila expandida, como é produzida a partir de argilominerais, possui elevado teor de $\mathrm{Al}_{2} \mathrm{O}_{3}, \mathrm{SiO}_{2}$, além de $\mathrm{Fe}_{2} \mathrm{O}_{3}$, responsável pela cor vermelha após queima acima de 5\% [24]. A brita e argila expandida apresentam elevado teor de álcalis $\left(\mathrm{K}_{2} \mathrm{O}\right.$ $+\mathrm{Na}_{2} \mathrm{O}$ ), o que poderia influenciar na durabilidade devido à reação álcali agregado.

Tabela 3: Análise química.

\begin{tabular}{l|c|c|c|c|c|c|c|c|c|c}
\hline (\%) & $\mathbf{S i O}_{2}$ & $\mathbf{A l}_{2} \mathbf{O}_{3}$ & $\mathbf{C a O}$ & $\mathbf{F e}_{2} \mathbf{O}_{3}$ & $\mathbf{K}_{\mathbf{2}} \mathbf{O}$ & $\mathbf{M g O}$ & $\mathbf{N a}_{2} \mathbf{O}$ & $\mathbf{T i O}_{2}$ & $\mathbf{P}_{\mathbf{2}} \mathbf{O}_{5}$ & OUTROS \\
\hline Argila expandida & 60,5 & 20,3 & 0,4 & 7,9 & 5,0 & 3,69 & 0,61 & 0,87 & 0,21 & 0,20 \\
Brita & 68,2 & 14,4 & 3,4 & 3,5 & 3,5 & 2,08 & 3,5 & 0,54 & 0,17 & 0,30 \\
\hline
\end{tabular}

\subsection{Análise microestrutural}

A análise mineralógica foi realizada com o objetivo de identificar as fases presentes na argila, que servirá para orientação de trabalhos futuros. De acordo com a Figura 4, foi identificada a sílica livre que normalmente está presente nas argilas como material acessório, a hematita decorrente do elevado teor de $\mathrm{Fe}_{2} \mathrm{O}_{3}$, além da fase espinélio, decorrente da presença da $\mathrm{SiO}_{2}$ e $\mathrm{MgO}$, que está de acordo com outras pesquisas [30]. Segundo Oliveira (2007) [31], a argila não apresenta atividade pozolânica, pois segundo a difratometria de raios X, a metacaulinita, esperada nesse tipo de material, deu lugar aos espinélios, provavelmente porque a argila expandida foi queimada em temperaturas acima de $1100^{\circ} \mathrm{C}$. Portanto, os álcalis estão presentes na forma de fases cristalinas como feldspato e são inócuos na reação álcalis agregado. 


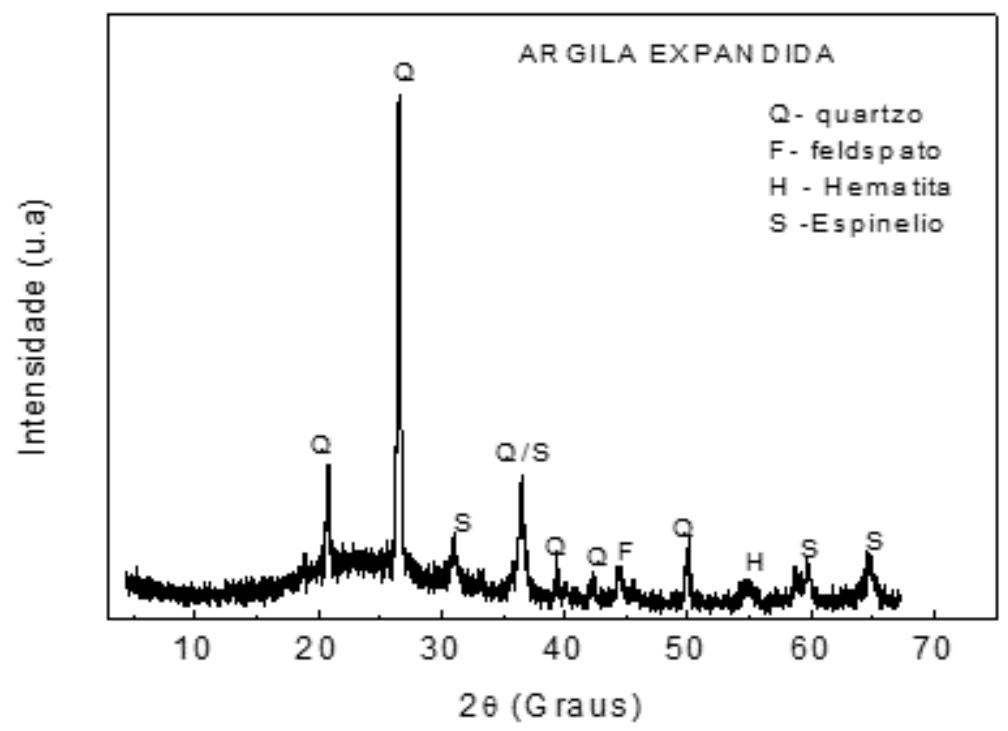

Figura 4: Padrão de difratometria de raios $X$ da argila.

\subsection{Análise granulométrica}

A análise granulométrica das argilas expandidas é apresentada na Figura 5. De acordo com análise da uniformidade segundo a equação $\mathrm{Cu}=\mathrm{D}_{60} / \mathrm{D}_{10}$ [32], a argila de $15 \mathrm{~mm}$ apresenta uniformidade média, enquanto as argilas de 5 e $22 \mathrm{~mm}$ são muito uniformes, ou seja, essas argilas apresentam grande porcentagem de grãos em uma faixa estreita de dimensão, sendo inadequadas para uso pelo grande número de vazios que pode gerar na mistura. Considerando a concavidade dada pela fórmula $\mathrm{Cc}=\mathrm{D}_{30}{ }^{2} / \mathrm{D}_{60} . \mathrm{D}_{10}$, as argilas 22 e 5 mm são mal graduadas enquanto a argila de $15 \mathrm{~mm}$ é classificada como bem graduada [32]. Assim, somente a argila com $15 \mathrm{~mm}$ inicialmente é mais adequada para realizar misturas. De modo geral, é fundamental que se utilizem argilas com distribuição granulométrica bem graduada e de uniformidade média para garantir o empacotamento maior possível.

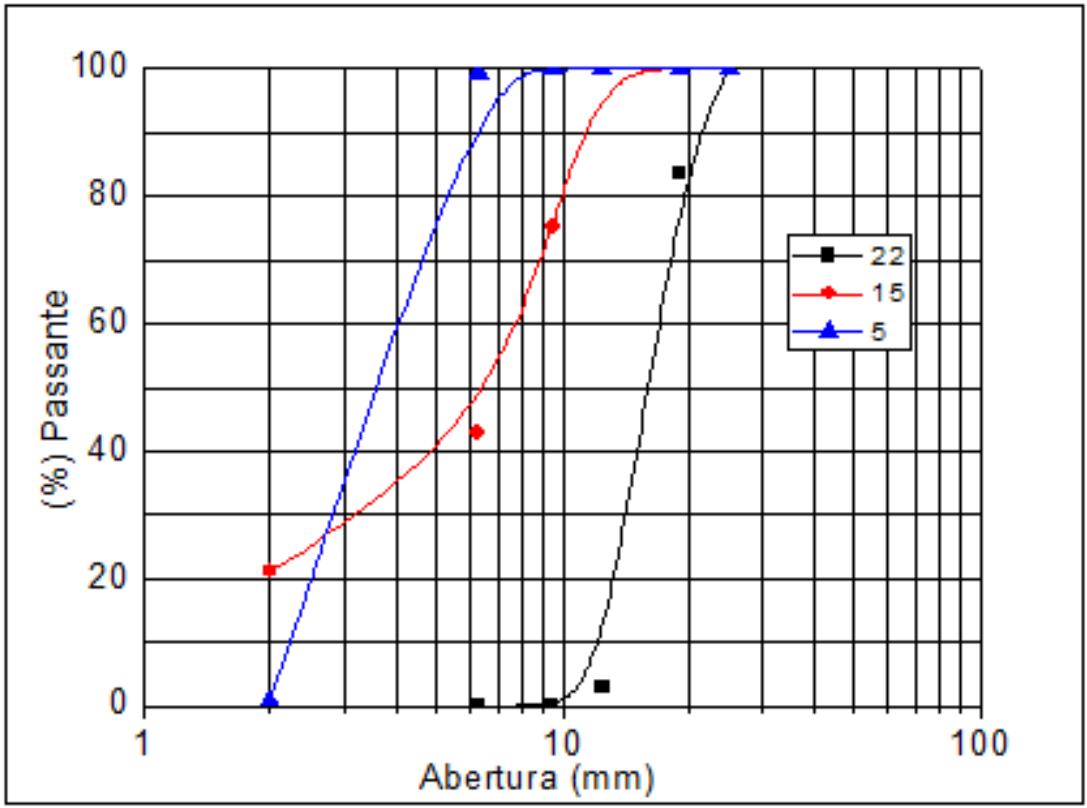

Figura 5: Análise granulométrica das argilas.

\subsection{Abatimento}

$\mathrm{Na}$ Tabela 4, é apresentado o abatimento das formulações, cujo valor foi determinado de acordo com a norma 
NBR NM 67/2011 [33]. Sabe-se que o teor de água necessário para produzir um abatimento depende de vários fatores e que mais água é necessária quando se utiliza um agregado angular e com textura áspera [34]. Os abatimentos das formulações apresentaram diferenças sendo que a formulação B $(16 \mathrm{~cm})$ apresentou maior abatimento enquanto a formulação $\mathrm{D}(5 \mathrm{~cm})$ resultou no menor abatimento, fato que pode influenciar na resistência final do concreto. Como foi mantida a mesma relação a/c em cada mistura, acredita-se que a diferença apresentada no teste de abatimento entre as formulações pode ser devido ao arranjo granulométrico, sobretudo na formulação B, que apresentou menor massa unitária, conforme apresentado na Figura 1 e, consequentemente, menor área específica, que, segundo Isaia (2005) [22], sugere que a água tendo menos área para molhar, induz a uma maior trabalhabilidade. Quanto ao resultado do abatimento, para formulação D, pode ser explicado pelo fato de essa possuir maior adição do agregado de maior diâmetro (Ø22 e $15 \mathrm{~mm}$ ), favorecendo ao acréscimo da massa unitária, o que resulta na perda da consistência do concreto.

O abatimento é fundamental para garantir que todas as formulações apresentem o mesmo espaçamento entre partículas antes da conformação dos corpos de prova, para que não ocorra influência nos resultados da resistência mecânica e, proporcionalmente, na densidade após cura. Por outro lado, a correção do abatimento muitas vezes não é possível somente alterando a água, sendo necessário alterar a proporção de agregado miúdo e/ou cimento. Neste trabalho, os resultados do abatimento foram diferentes em função do arranjo granulométrico e da área especifica da mistura.

Tabela 4: Teste de abatimento das formulações.

\begin{tabular}{l|c|c|c|c|c}
\hline FORMULAÇÕES & PADRÃO & A & B & C & D \\
\hline Abatimento $(\mathrm{cm})$ & 12 & 8 & 16 & 13 & 5 \\
\hline
\end{tabular}

\subsection{Densidade}

Os dados da densidade são apresentados na Figura 6. Foram analisados utilizando o software ANOVA com $5 \%$ de significância [35]. Os dados mostram que são significativos e que apresentam diferenças entre as formulações. A massa padrão produzida com brita convencional apresentou maior densidade $\left(2250 \mathrm{Kg} / \mathrm{dcm}^{3}\right)$ em relação às demais produzidas com argila expandida. O peso da placa padrão obtido foi de $29 \pm 0,1 \mathrm{Kg}, \mathrm{e}$, proporcionalmente, houve redução no peso e densidade nas formulações: A (42\%), $(52 \%), \mathrm{C}(40 \%)$ e $\mathrm{D}(30 \%)$. Portanto, a substituição do agregado leve pela brita apresentou alterações no peso da placa. Vale ressaltar que a densidade da formulação $\mathrm{D}$ foi a maior em relação às argilas expandidas, provavelmente devido ao menor abatimento, além do maior valor da massa unitária plotado no diagrama ternário apresentado na Figura 1.

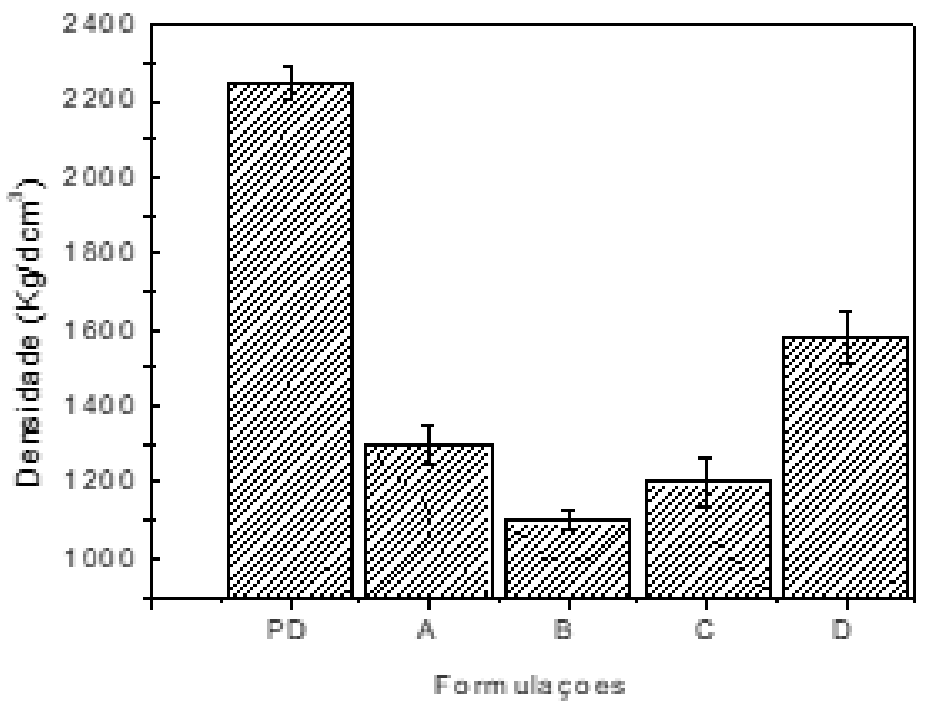

Figura 6: Formulações em função da densidade.

\subsection{Resistência Mecânica a flexão em três pontos (RMF)}

Os dados da RMF estão apresentados na Figura 7. De acordo com a NBR 15805/2015 [36], a RMF mínima 
aceitável é 3,5 MPa, para placas de concreto. Os dados foram analisados pelo software ANOVA com 5\% significância e as formulações padrão, A e D são significativos. Logo, pode afirmar que os resultados das formulações padrão, A e D são iguais. Assim, essas formulações são adequadas para substituir as britas. Foi observado que as formulações A e D apresentaram valores próximos de densidade no ensaio de empacotamento, conforme apresentado na Figura 1, e abatimento, conforme apresentado na Tabela 4. Apesar das diferenças entre absorção de água entre as argilas e, proporcionalmente, da resistência mecânica, não ficou claro que a massa unitária é fundamental para que ocorra desenvolvimento da resistência durante a cura. Os resultados de densidade aparente mais baixos ou mais altos não provaram que influenciam na resistência mecânica a flexão. Embora em estudos de Dilli [37], em que misturou três tipos de argila expandida, foi observado que, para misturas em que os corpos de prova de concreto apresentaram menor densidade, foram os que apresentaram maior resistência para maiores idades > 56 dias, em função do desenvolvimento da cura interna que ocorre progressivamente com o tempo.

Neste estudo, nota-se uma relação entre o abatimento e a resistência mecânica a flexão, pois, para menores abatimentos, nas formulações A e $\mathrm{D}$, obtiveram-se valores próximos de resistência a flexão em comparação com a formulação padrão já que menor abatimento contribuiu para maior aproximação das partículas durante a cura e consequentemente, ganho de resistência.

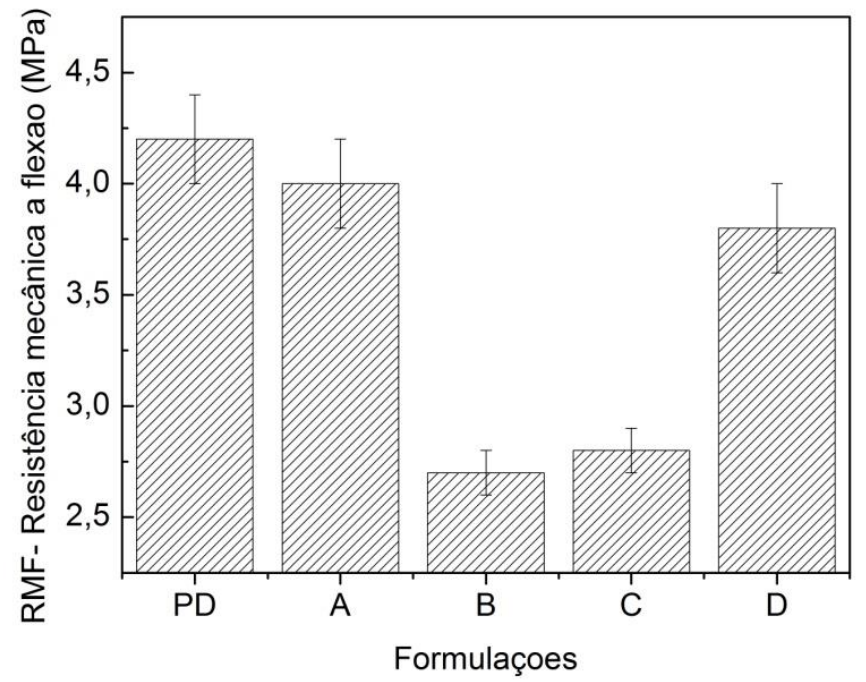

Figura 7: Resistência mecânica à flexão em três pontos das placas.

De acordo com a Figura 8, foi observado que existe uma correlação entre a distribuição granulométrica e a resistência final do concreto. Densidades baixas $<0,68$, bem como densidades mais elevadas $>0,84$, sobretudo com o acréscimo da argila de $5 \mathrm{~mm}$, não apresentaram bons resultados, provavelmente porque a distribuição granulométrica inicial desta argila não estava regular. Foi encontrada uma faixa de 0,7 e 0,8 em que se obtiveram resultados de resistência dentro da norma. 


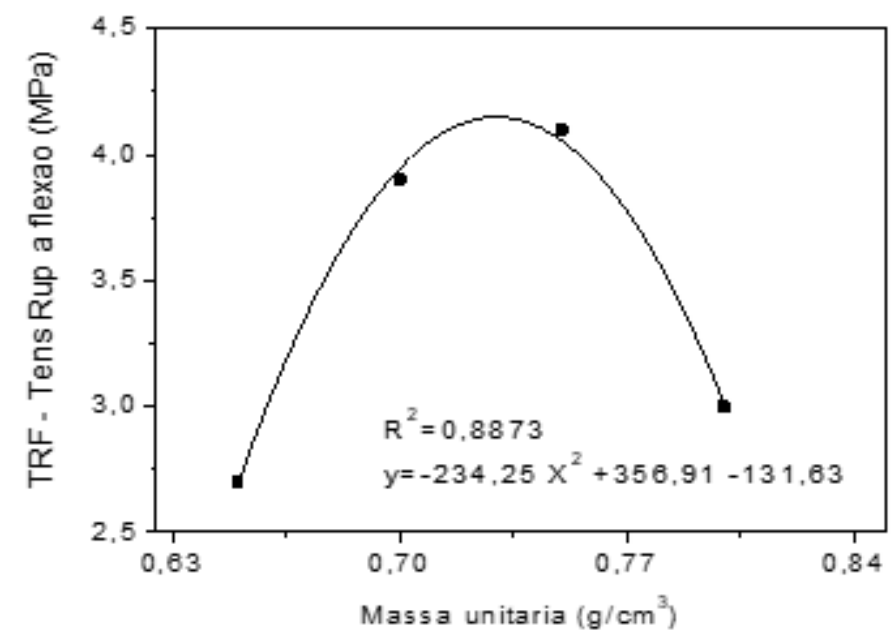

Figura 8: Densidade de empacotamento x tensão de ruptura à flexão.

\section{CONCLUSÕES}

A proposta da pesquisa foi produzir placas de baixo peso para facilitar o manuseio e transporte sem alteração da resistência mecânica. Após os resultados obtidos nesta pesquisa foi possível concluir que, a brita e argila expandida apresentam elevado teor de álcalis que podem influenciar na durabilidade das placas de concreto devido a reações álcali agregado. Por sua vez, estudos mostram que os álcalis presentes na argila expandida são inócuos, pois estão presentes na forma de feldspatos.

A distribuição granulométrica dos agregados é fundamental para se obter um empacotamento e abatimento adequados. $\mathrm{O}$ abatimento, provavelmente, influenciou na resistência mecânica do produto final, sobretudo nas formulações A e D. Este fato se deve ao arranjo granulométrico que favoreceu o aumento da área específica da mistura.

As formulações A e D podem substituir a brita na formulação proposta, pois atendem a exigência mínima de resistência mecânica a flexão de 3,5 MPa, apresentando com menor densidade comparadas com a formulação padrão.

Todas as formulações com argila expandida apresentaram redução na densidade de 42\%,52\%,40\% e $30 \%$ para formulações A, B, C e D, respectivamente.

O empacotamento determinado por meio da massa unitária influiu na resistência mecânica quando ficou na faixa entre 0,7 e $0,8 \mathrm{~g} / \mathrm{cm} 3$.

Considerando que uma placa originalmente pesava cerca de $30 \pm 0,1 \mathrm{Kg}$, foi possível produzir uma nova placa com peso de cerca de $20 \pm 0,1 \mathrm{Kg}$ mantendo a mesma resistência mecânica a flexão em relação a formulação padrão.

\section{BIBLIOGRAFIA}

[1] UNAL, O., UYGYNOGLU T., YILDEZ A., "Investigation of properties of low-strength lightweight concrete for thermal insulation”, Building and Environment, v. 42, pp. 584-590, 2007 .

[2] OZGUVEN.A., GUNDUZ L., "Examination of effective parameters for the production of expanded clay aggregate", Cement and Concrete composites, v.34,pp. 781-787, 2012.

[3] ROSSIGNOLO,J.A. "Properties of High-Performance LWAC for Precast Structures With Brazilian Lighweight Aggregates", Cement \& Concrete Composites, v. 253, n 1, p. 77-82, 2006.

[4] CHANDRA, S. BERNTSSON, L. Lightweight aggregate concrete: Science, technology, and applications. Noyes Publications, USA, p.409, 2002.

[5] DOMAGATA, L., "The effect of lightweight aggregate water absorption on the reduction of watercement ratio in fresh concrete, "Procedia Engineerin", v. 108, pp. 206-2013, 2016.

[6] COSTA, H., JULIO, E., LOURENÇO, J. "New approach for shrinkage prediction of high strength lightweight aggregate concrete", Construction and Building Materials, v. 35, pp. 84-91, 2012. 
[7] ROSSIGNOLO, J.A. "Influence Avaliação da zona de transição interfacial pasta agregado leve em concretos com sílica ativa e látex", Revista Matéria, v. 12, n. 3, 2007.

[8] BOGAS, A. GOMES, A. "Compressive behavior and failure modes of structural lightweight aggregate concrete - Characterization and strength prediction", Materials and Design, v.46, pp.832-834, 2013

[9] ABNT. "ABNT/NBR NM 45: 2006 - Agregados - determinação da massa unitária e do volume de vazio procedimento". Rio de Janeiro, ABNT, 2012.

[10] ABNT. "ABNT/NBR NM:248- agregados- Determinação da composição granulométrica,Rio de Janeiro, ABNT, 2003.

[11] ABNT."ABNT/NBR 8916/2015 - Adesivos e selantes - determinação da densidade - via picnômetro." Rio de Janeiro, ABNT, 2015.

[12] Instruction Manual Multivolume Pycnometer Micromeritics 1305 (2013). Disponível em https://www.dcu.ie/sites/default/files/mechanical_engineering/images/DCU_Pycnometer.Acessado em 20.09.2016

[13] ABNT. “ABNT/NBR NM 53: 2009 -Agregado graúdo - Determinação da massa específica, massa específica aparente e absorção de água". Rio de Janeiro, ABNT, 2009.

[14] SOLTAN, A. M, KAHL, W.A., EL-RAOOF, F.ABD., et al., 2016, "Lightweight aggregates from mixtures of granite wastes with clay", Journal of Cleaner Production, v.117, pp.139-149.

[15] CINEXPAN. Disponível em http://www.cinexpan.com.br/. Acessado em 15.08.2016.

[16] TERZIAN, P., HELENE P. R. L. Manual de dosagem e controle do concreto, Ed. PINI, S. Paulo, SP (1992).

[17] CABRAL, A. E. B., SCHALCH, V., MOLI, D. C. C. et al. "Desempenho de concretos com agregados reciclados de cerâmica vermelha",Cerâmica,v. 55, pp.448-460, 2009.

[18] GOLIAS,M.,CASTRO J., WEISS, J., "The influence of the initial moisture content of lightweight aggregate on internal curing", Construction and Building Materials, v.35, pp. 52-62, 2012.

[19] COSTA, H., JULIO, E., LOURENÇO, J., "New approach for shrinkage prediction of high strength lightweight aggregate concrete", Construction and Building Materials, v.35,pp.84-91 84-91, 2012.

[20] LIJUAN, K., LIRONG H., "Chemical reactivity of lightweight aggregate in cement paste", Construction and Building Materials, v. 64, pp. 22-27. 2014.

[21] ABNT. “ABNT/NBR 12142/2010 : concreto- determinação da resistência à flexão de corpos de prova prismático-procedimento”.Rio de Janeiro, ABNT,2010.

[22] ISAIA, G. C. “Concreto: ensino, pesquisa e realizações”, In: Ibracon, São Paulo, pp 953-983, 2005.

[23] CABRAL, E.M., SA, R.J., VIEIRA,R.P. “Utilização de massas cerâmicas na produção de agregado sintético de argila calcinada para uso em concreto", Cerâmica,v. 54, pp 404-410, 2008.

[24] SANTOS, P.S. Tecnologia de Argilas, In: Blucher, São Paulo,1989

[25] GOLIAS, M., CASTRO, J., WEISS, J., et al., "The influence of the initial moisture content of lightweight aggregate on internal curing", Construction and Building Materials, Elsevier, v.35, pp. 52-62, 2012.

[26] LOURENÇO, J., JULIO, E., LOURENÇO, J., et al., "New approach for shrinkage prediction of high strength lightweight aggregate concrete", Construction and Building Materials, v. 35, pp. 84-91, 2012.

[27] KOHNO, K., OKAMOTOA, T., ISIKAWAA, Y., et al. "Effects of artificial lightweight aggregate on autogenous shrinkage of concrete", Cement and Concrete Research, v.29, n.4, 1998.

[28] OLLIVIER, B. "Bourdette. Interfacial transition zone in concrete. Advanced", Cement Based Materials, v.2, n.1, pp.130-138, 1995.

[29] GOLIAS, M., CASTRO, J., WEISS, J., et al., "The influence of the initial moisture content of lightweight aggregate on intenal curing", Construction and Building Materials. v.35, pp. 52-62, 2012.

[30] QUINA,M. J., ALMEIDA M. A., SANTOS, R. "Compatibility analysis of municipal solid waste incineration residues and clay for producing lightweight aggregates", Applied Clay Science, v.102, pp. 71-80, 2014

[31] OLIVEIRA. C.A.S. Avaliação Microestrutural e comportamento físico e mecânico de concretos de alto desempenho produzidos com metacaulim, Tese de D.Sc, UFMG, Minas Gerais, MG, Brasil, Dezembro de 2007

[32] CAPUTO, H.P. Mecânica dos Solos e suas aplicações. 6 ed., v.1, 2011 
[33] ABNT. "ABNT/NBR NM 67: concreto - determinação da consistência pelo abatimento do tronco de cone- procedimento”. Rio Janeiro, ABNT, 2011.8p.

[34] VAIRAGADE, S., S.H., KENE, V.S. "Combine effect of rice husk ash and fly ash on concrete by $30 \%$ cement replacement”, Procedia Eng., v. 51, pp. 35-44, 2013.

[35] WALPOLE, R.E., MYERS R.H. Probabilidade e Estatística para Engenharia. Pearson Education, Brazil, 2009

[36] ABNT “ABNT/ NBR 15805: concreto- pisos elevados de placas de concreto - requisitos e procedimentos". Rio de Janeiro, ABNT, 2014.

[37] DILLI, M. E., ATAHAN, H. N., SENGÜl, C. "A comparison of strength and elastic properties between conventional and lightweight structural concretes designed with expanded clay aggregates, "Construction and Building Materials", v. 101, pp. 260-267, 2015. 